\title{
WEIGHTED ESTIMATES FOR ITERATED COMMUTATORS OF MULTILINEAR OPERATORS WITH NON-SMOOTH KERNELS
}

\author{
XiuXiang Peng, Zengyan Si And Qingying Xue
}

Abstract. Let $T$ be the multilinear Calderón-Zygmund operator with non-smooth kernels and $T_{*}$ be its corresponding maximal function. In this paper, we give the weighted strong type estimates and weak end-point estimates for the iterated commutators of multilinear operator $T_{*}$. Similar results still hold for the operator $T$.

Mathematics subject classification (2010): 42B20, 47G10.

Keywords and phrases: Maximal multilinear operators, multiple weights, generalized Calderón-Zygmund operator, commutators.

\section{REFERENCES}

[1] B. T. ANH AND X. T. DuONG, On commutators of vector BMO functions and multilinear singular integrals with non-smmoth kernels, J. Math. Anal. Appl. 371 (2010), 80-84.

[2] S. Chanillo, A note on commutators, Indiana Univ. Math. J. 44 (1982), 7-16.

[3] S. Chanillo, D. K. Watson AND R. L. Wheeden, some integral and maximal operators related to starlike sets, Studia Math. 107 (1993), 223-255.

[4] X. CHEN, Weighted estimates for maximal operator of multilinear singular intergral, to appear in Bull. Polish Acad. Sci. Math.

[5] X. Chen And Q. XUE, Weighted estimates for a class of multilinear fractional type operators, J. Math. Anal. Appl. 362, 2 (2010), 355-373.

[6] R. R. COIFMAN AND Y. MEYER, On commutators of singular integrals and bilinear singular integrals, Trans. Amer. Math. Soc. 212 (1975), 315-331.

[7] R. R. COIFMAN And Y. MeYer, Commutateurs d'intégrales singuliè res et opérateurs multilinéaires, Ann. Inst. Fourier, Grenoble 28 (1978), 177-202.

[8] R. R. Coifman and Y. Meyer, Au-delà des opérateurs pseudo-différentiels, Asterisque 57 (1978).

[9] R. R. Coifman, Y. Rochberg And Y. Meyer, Factorization theorems for Hardy spaces in several variables, Ann. of. Math. 103 (1976), 611-635.

[10] X. T. Duong AND A. McIntosh, Singular Integral Operators with Non-smooth Kernels on Irregular Domains, Rev. Mat. Iberoamericana 15 (1999), 233-265.

[11] X. T. Duong And D. W. Robinson, Semigroup Kernels, Poisson Bounds, and Holomorphic Functional Calculus, J. Funct. Anal., 142 (1996), 89-128.

[12] C. FefFerman And E. M. STein, $H^{p}$ spaces of several variables, Acta Math. 129 (1972), 137-193.

[13] L. GRAFAKOS, L. LIU AND D. YANG, Multiple weighted norm inequalities for maximal multilinear singular integrals with non-smooth kernels, Proceedings of the Royal Society of Edinburgh, to appear.

[14] L. Grafakos And J. Martell, Extrapolation of Weighted Norm Inequalities for Multivariable Operators and Applications, The Journal of Geometric Analysis, 14 (2004), 19-46.

[15] L. Grafakos And R. Torres, Multilinear Calderón-Zygmund theory, Adv. Math. 165 (2002), $124-164$.

[16] L. Grafakos, R. H. Torres, Maximal operator and weighted norm inequalities for multilinear singular integrals, Indiana Univ. Math. J. 51, 5 (2002), 1261-1276. 
[17] L. Grafakos And R. Torres, On multilinear singular integrals of Calderón-Zygmund type, Publ. Mat. (2002) Extra, 57-91.

[18] A. K. Lerner, S. Ombrosi, C. Pérez, R. H. Torres and R. Trujillo-González, New maximal functions and multiple weights for the multilinear Calderón-Zygmund theory, Adv. Math. 220, 4 (2009), 1222-1264.

[19] G. R. Ming AND J. LI, Sharp maximal functions estimates for multilinear singular integrals with non-smooth kermels, Anal. Theory Appl. 25, 4 (2009), 333-348.

[20] K. Moen, Weighted inequalities for multilinear fractional integral operators, Collect. Math. 60 (2009), 213-238.

[21] B. Moukenhoupt, Weighted norm inequalities for the Hardy maximal function, Trans. Am. Math. Soc. 165 (1972), 207-226.

[22] C. PEREZ, Endpoint estimates for commutators of singular integral operators, J. Funct. Anal. 128 (1995), 163-185.

[23] C. PEREZ AND R. H. TORRES, Sharp maximal function estimates for multilinear singular integrals, Harmonic Analysis at Mount Holyoke, Contemporary Mathematics 320 (2003), 323-331.

[24] C. Perez And R. Trujillo-GonZalez, Sharp weighted estimates for multilinear commutators, J. London Math. Soc. 65, 3 (2002), 672-692.

[25] C. Pérez, G. Pradolini, R. H. Torres, and R. Trujillo-GonZalez, End-point estimates for iterated commutators of multilinear singular integrals, preprint, arXiv:1004.4976.

[26] C. Perez, G. Pradolini, R. Torres, R. Trujillo-Gonzalez, Endpoint estimates for iterated commutators of multilinear singular integrals, arXiv:1004.4976v2, March, 2011.

[27] M. M. Rao And Z. D. Ren, Theory of Orlicz Spaces, Monographs and Textbooks in Pure and Applied Math. 146, Marcel Dekker, New York, 1991.

[28] Q. XUE, Weighted estimates for the iterated commutators of multilinear maximal and fractonal type operators, arxiv:1105.4471v1 [math.CA] 23 May, 2011. 